\title{
Optimal placement units of distributed generation
}

\author{
I. Chernykh ${ }^{1}$, D. Chechushkov ${ }^{1} \&$ T. Panikovskaya ${ }^{2}$ \\ ${ }^{I}$ Department of High Voltage Engineering, \\ Ural Federal University, Russia \\ ${ }^{2}$ Department of Automated Electric Systems, \\ Ural Federal University, Russia
}

\begin{abstract}
In this paper a new approach to solve the problem of optimal placement of distributed generation sources is proposed. The method is aimed at improving the reliability of electricity supply. The mathematical model of the optimal placement of distributed generation sources (DG) based on improving the reliability of power supply as the optimization algorithm used a genetic algorithm. The results of experimental calculations and comparative analysis of the algorithm is shown.

Keywords: distributed generation sources, the stability of the power source, the objective function, optimization
\end{abstract}

\section{Introduction}

The main objective of the electricity is reliable and quality supply of electricity to consumers. In particular, is very important for enterprises with continuous or complex technology industries. Many of these power systems are operating closer to the limit of stability. Currently intensively developed measures to improve the reliability of power supply, and one of these events becomes placement of distributed generation sources in the power system near the consumer.

Distributed generation is represented decentralized sources of electricity and heat relatively small capacity, from tens of $\mathrm{kW}$ up to $50 \mathrm{MW}$. The main idea of DG is to connect sources of electrical energy on the side carrying supplies consumer. One of the main problems is the optimal allocation of DG sources. 
Problem of optimal placement of sources DG reduced to finding the best node to connect and economically beneficial to the power level of the source [1-8]. Previous researchers in the formulation of the optimization problem of accommodation sources DG used the different criteria: minimizing power loss [9], profit maximization [10], minimizing the cost [11], a multiobjective function taking into account different criteria $[12,13]$.

However, no studies that address the problem of improving the reliability of power supply due to the optimal location of the sources of the DG. Many works which reveal the theme of sustainable sources of DG and power systems in which they operate $[14,15]$ in $[16,17]$ reflected the impact of research on sources of DG emergency operation modes of power systems.

In this paper, the authors propose an approach that takes into account the optimizing the placement of sources DG and the stability of the electricity system and the stability of the source of DG. This will save on activities to improve the reliability of sources of DG during the operational phase.

\section{Problems formulation}

Optimization of DG placement - is a complex task, which should take into account the combined effect of DG work with distribution network. What must be considered is the impact of DG on the stability of the power system and sustainability of the source of DG. When this problem is solved it will be the most advantageous option in economic and technological terms. To simplify the problem it was divided into two stages:

In the first stage the problem of finding the optimum power by DG power supply reliability and stability of the power system. When planning and conducting of operation mode of power system must take into account many constraints and influencing factors. First, it is the technological limitations of the power of electrical equipment. In addition there is a large group of constraints associated with the stability of synchronous operation of the power system as a whole. Operational boundaries defined steady state restrictions flows between synchronies regions of grid. When exceeding the allowable flows reduced reliability mode, and under the influence of even minor disturbances in the power system, it may be an asynchronous course, the elimination of which would require opening the network and/or restriction of consumption, which is unacceptable for industrial enterprises. To simplify the task of monitoring power flows, isolated group of lines connecting the power districts, and combine them in a so-called section. Power flow in a section equal to the sum of flows belonging to a line. If the current flow is within the limits - mode power system is valid. So for a particular power supply system allocated section, further use of variant calculations can determine the course that is included in the section off which lead to the most serious consequences. Regulation of flow in the cross section by changing the nodes generate electrical network by connecting DG sources. Knowing this dependence can be determinate the optimal power of DG source for input flows in the specified limits. 
At the second stage, the best connection point source and the optimal composition of the DG-generating equipment for the investment criteria. Investment criterion is a function that takes into account the costs except impact on a number of sources DG regime properties grid. The genetic algorithm is used for optimizing.

\section{Modeling technique}

Variation calculations to determine the most severe violations of the network and the calculation efficiency ratios were conducted in the software package InorXl, an additional component of MS Excel. Operation of the first phase can be represented in a block diagram shown in Fig. 1.

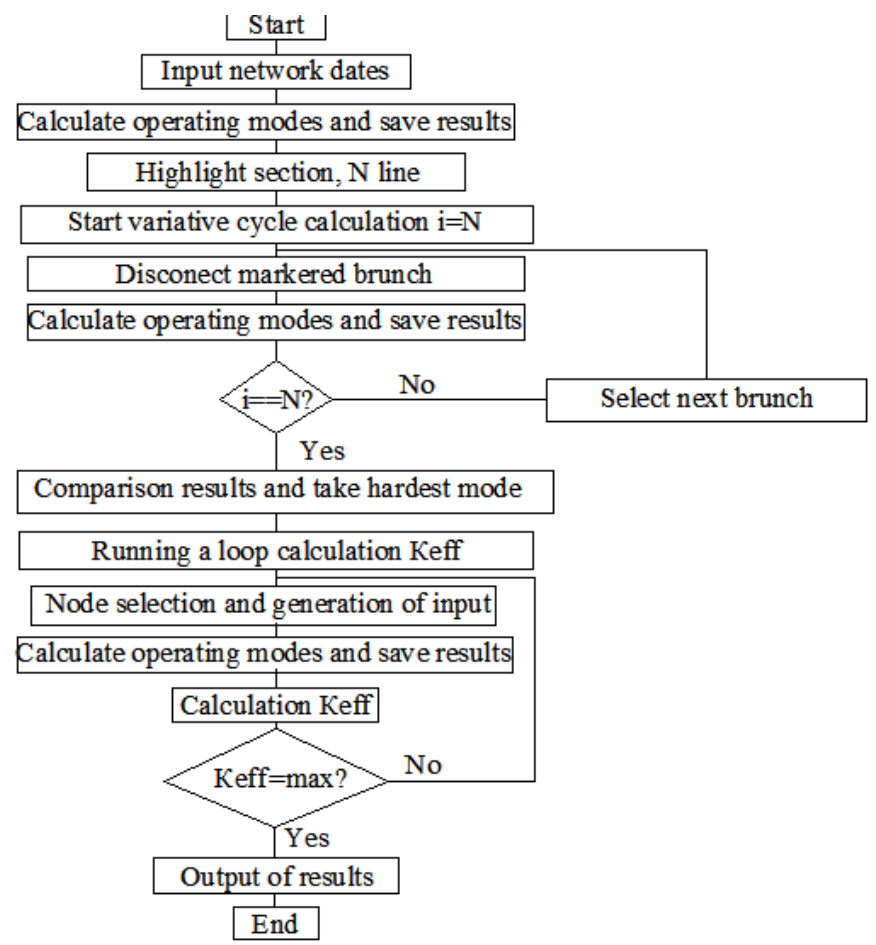

Figure 1: Block diagram of the first stage.

Effectiveness ratios are defined as a function:

$$
F_{3}=k_{\text {effij }}=\frac{\Delta P_{\text {overloadij }}}{\Delta P_{D G i j}}
$$

The algorithm in Figure 1 is implemented as a macro in Excel.

The second stage is necessary to make the optimization objective function, which integrates various economic factors. For such a function is proposed profitability index, the amount equal to the ratio of discounted cash flows to the 
initial cost. If the values of the above 1 , the project can be considered costeffective if the values are smaller than or equal to 1 that such a project can be rejected as unprofitable. This factor is convenient to take into account the limitations.

In solving the problem, you can take the design life and lay in the implementation of investment projects in modern Russian conditions $\mathrm{T} \approx 7$ years. In table 1, details reflect the capital cost of the project and the costs of operation of the station.

Table 1: Components of capital and operating costs.

\begin{tabular}{|c|c|c|c|}
\hline \multicolumn{2}{|c|}{ Capital expenditures (K) } & \multicolumn{2}{c|}{ Operating costs (C) } \\
\hline Cost component & Designation & Cost component & Designation \\
\hline $\begin{array}{c}\text { Purchase and installation of } \\
\text { equipment }\end{array}$ & $K_{1}$ & $\begin{array}{c}\text { Energy losses in the } \\
\text { network }\end{array}$ & $C_{1}$ \\
\hline Turnkey Construction & $K_{2}$ & Fuel & $C_{2}$ \\
\hline Transportation costs & $K_{3}$ & Purchase from EE & $C_{3}$ \\
\hline Project work & $K_{4}$ & $\begin{array}{c}\text { Purchase power from } \\
\text { network }\end{array}$ & $C_{4}$ \\
\hline Pipeline and DHW & $K_{5}$ & Repair and maintenance & $C_{5}$ \\
\hline
\end{tabular}

The profitable part of the project is formed from lower costs for the purchase of EE $D_{l}$ and reduced costs for the purchase of TE $D_{2}$. On this, the revenues of the project recorded the difference in cost of the purchase of electricity and the cost of its own energy efficiency, and also with the thermal energy. In this paper we adopted two more sources of income - reduction of environmental charges $D_{3}$, the example of extracting the oil company, and a decrease in oil production losses due to interruptions in electricity supply emergency $D_{4}$.

The paper does not consider the possibility of selling electricity on the side for two reasons. First - the power source selected at the first stage may be less than or equal to their own needs of the enterprise and there will be no spare capacity for sale. The second reason - power energy (PE) coast established marketing companies, usually below the cost of production on the PE from DG. This artificially created barriers to small generation to wholesale markets of PE. However, if you change this situation, the model must enter the appropriate indicator.

As a result, the objective function takes the following form:

$$
F_{1}=P \frac{\sum_{t}\left(D_{1}+D_{2}+D_{3}-C_{1}-C_{2}-C_{3}-C_{4}-C_{5}\right)^{t}}{K_{1}+K_{2}+K_{3}+K_{4}+K_{5}}
$$

where $P$ - total power sources DG.

Separately, we note limitations in the mathematical model. The first limitation choose throughput capacity of transformers, as sources are installed on the low voltage side and may give energy to the system power supply through these 
transformers substations. The transformers have a limited bandwidth, and this restriction must be taken into account by the following inequality:

$$
P_{D G i} \cdot\left(n_{i j}+n_{p i}\right)-k_{i j} \cdot P_{i} \leq S_{n} \cdot \cos \varphi
$$

where $\mathrm{S}_{\mathrm{n}}$ - the capacity of the transformer $\mathrm{kVA}$; $\cos \varphi$ - power factor.

\section{Test grid and results}

The proposed method was experimental calculations on the basis of the existing power supply system oilfield. A single-line diagram of the test network is shown in Fig. 2.

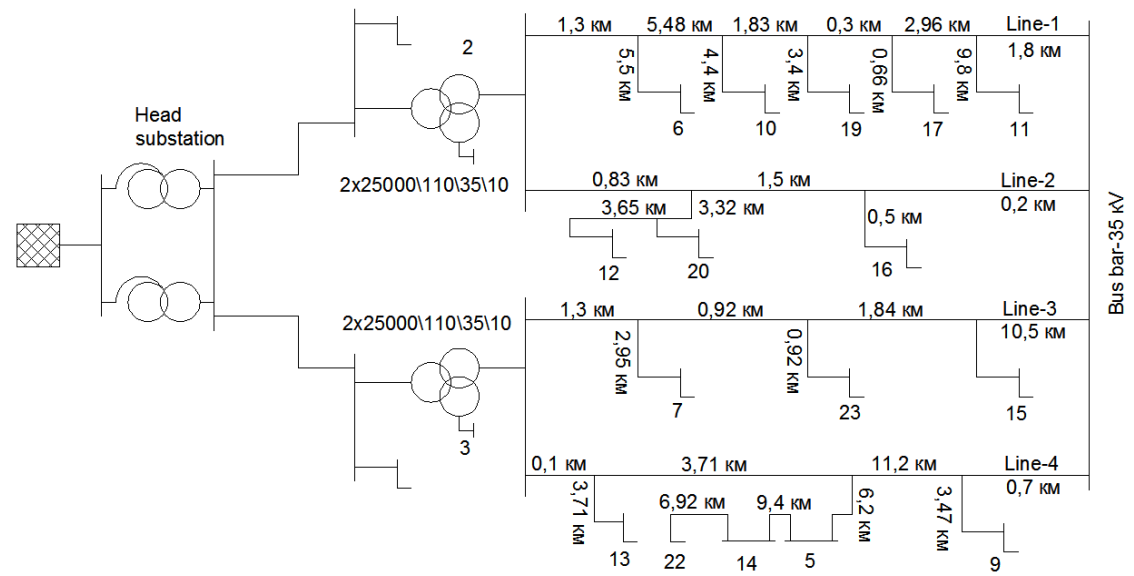

Figure 2: Single-line diagram of the test grid.

Table 2: $\quad$ Power loads of oilfield.

\begin{tabular}{|c|c|c|}
\hline Substation № & 1 bus bar, MVA & 2 bus bar, MVA \\
\hline 11 & $2.7+\mathrm{i} 0.9$ & $3.2+\mathrm{i} 1.12$ \\
\hline 17 & $0.25+\mathrm{i} 0.1$ & 0 \\
\hline 19 & $0.54+\mathrm{i} 0.29$ & $0.06+\mathrm{i} 0.07$ \\
\hline 10 & $2+\mathrm{i} 1.7$ & $1.3+\mathrm{i} 1.68$ \\
\hline 6 & $0.2+\mathrm{i} 0.45$ & $1+\mathrm{i} 0.84$ \\
\hline 16 & $2.5+\mathrm{i} 1.18$ & $2.4+\mathrm{i} 1.21$ \\
\hline 20 & $0.6+\mathrm{i} 0.43$ & $1+\mathrm{i} 0.77$ \\
\hline 12 & $3.2+\mathrm{i} 0.95$ & $3.4+\mathrm{i} 1.35$ \\
\hline 15 & $0.82+\mathrm{i} 0.9$ & $0.6+\mathrm{i} 0.6$ \\
\hline 23 & $0.56+\mathrm{i} 0.675$ & $0.36+\mathrm{i} 0.9$ \\
\hline 7 & $1+\mathrm{i} 0.45$ & $1.3+\mathrm{i} 1.4$ \\
\hline 9 & $0.7+\mathrm{i} 0.675$ & $0.5+\mathrm{i} 0.775$ \\
\hline 5 & $1.3+\mathrm{i} 0.4$ & $1.5+\mathrm{i} 0.3$ \\
\hline 14 & $1.8+\mathrm{i} 0.7$ & $1.5+\mathrm{i} 0.6$ \\
\hline 22 & $0.78+\mathrm{i} 0.73$ & $0.39+\mathrm{i} 0.69$ \\
\hline 13 & $2+\mathrm{i} 0.15$ & $1.9+\mathrm{i} 0.2$ \\
\hline
\end{tabular}


Resistivities of lines are $0.250 .4 \mathrm{Ohm} / \mathrm{km}$.

Data on transformers in substations are shown in Table 3.

Table 3: Dates of transformers.

\begin{tabular}{|c|c|c|c|c|c|c|}
\hline Substation & $\begin{array}{c}\mathrm{R}, \\
\text { Om }\end{array}$ & X, Om & G, Sm & B, Sm & Kt & $\begin{array}{c}\text { S, } \\
\text { kVA }\end{array}$ \\
\hline 11 & 1.48 & 24.4 & 7.51 & 46.3 & 0.177 & 6300 \\
\hline 17 & 2.72 & 24.4 & 5.44 & 32.7 & 0.175 & 4000 \\
\hline 19 & 2.72 & 24.4 & 5.44 & 32.7 & 0.175 & 63000 \\
\hline 10 & 1.48 & 24.4 & 7.51 & 46.3 & 0.177 & 4000 \\
\hline 6 & 2.72 & 24.4 & 5.44 & 32.7 & 0.175 & 16000 \\
\hline 16 & 0.436 & 8.2 & 13.3 & 65 & 0.174 & 16000 \\
\hline 20 & 2.72 & 24.4 & 5.44 & 32.7 & 0.175 & 4000 \\
\hline 12 & 0.788 & 10.5 & 9.23 & 44.3 & 0.174 & 10000 \\
\hline 15 & 2.72 & 24.4 & 5.44 & 32.7 & 0.175 & 10000 \\
\hline 23 & 2.72 & 24.4 & 5.44 & 32.7 & 0.175 & 10000 \\
\hline 7 & 2.72 & 24.4 & 5.44 & 32.7 & 0.175 & 6300 \\
\hline 9 & 2.72 & 24.4 & 5.44 & 32.7 & 0.175 & 6300 \\
\hline 5 & 2.72 & 24.4 & 5.44 & 32.7 & 0.175 & 4000 \\
\hline 14 & 0.436 & 8.2 & 13.3 & 65 & 0.174 & 16000 \\
\hline 22 & 2.72 & 24.4 & 5.44 & 32.7 & 0.175 & 6300 \\
\hline 13 & 0.788 & 10.5 & 9.23 & 44.3 & 0.174 & 10000 \\
\hline
\end{tabular}

This power system is characterized as extremely scarce. Electricity shortage here due to the fact that the capacity of electricity has reached a critical point, which cannot be increased. In the event of an accident on the $110 \mathrm{kV}$ lines partially or completely de-energized objects field, resulting in serious economic losses. According to the results of variant calculations becomes the most severe violation of the output of the transformer T1 was situated on substation №2, which leads to a $50 \%$ overload of lines included in the section. Calculation of efficiency coefficients showed that the best connection points for DG sources are second bus bars in substations №16 and 17, with a minimum capacity of $6 \mathrm{MW}$ of each source.

To optimize the investment criteria two nodes with the lowest efficiency ratios are selected (Table 4 ).

Modeling components of the optimization function of the investment criteria described unit values per $\mathrm{kW}$ of installed capacity. Most economic indicators piston units with sufficient accuracy by the linear and quadratic functions. Fig. 3 shows the dependence of the cost cogenerations different manufacturers of their rated capacity, defined by the expression

$$
K_{1}=\sum_{i=1}^{N}\left(n_{i}+n_{p i}\right) \cdot\left(a_{1}+a_{2}\right) \cdot P_{D G i}
$$

where $\mathrm{n}_{\mathrm{i}}, \mathrm{n}_{\mathrm{pi}}$ - the number of workers and possible reserve units in the $i$-th node; $\mathrm{P}_{\mathrm{DGi}}$ - rated power of DG source in the $i$-th node; $\mathrm{a}_{1}$ and $\mathrm{a}_{2}$ - coefficients of the linear approximation. 
Table 4: Values $K_{\text {eff }}$ for substations 17,16 and 11.

\begin{tabular}{|c|c|c|c|c|c|}
\hline \multirow{2}{*}{$\begin{array}{c}\text { Variant } \\
\text { number }\end{array}$} & $\begin{array}{c}\text { Group } \\
\text { line } \\
\text { number }\end{array}$ & $\begin{array}{c}\text { Emergency } \\
\text { circuit }\end{array}$ & $\begin{array}{c}\text { Substation } \\
\text { and } \\
\text { section of } \\
\text { bus bars }\end{array}$ & $K_{\text {eff }}$ & Note \\
\hline \multirow{2}{*}{1} & \multirow{2}{*}{1} & \multirow{2}{*}{$\begin{array}{c}\text { Substation } \\
\text { №2 T1 }\end{array}$} & II -17 & 0,482 & Loading DG sources \\
\cline { 4 - 6 } & & & II -11 & 0,130 & Loading DG sources \\
\cline { 4 - 6 } & & & II-16 & 0,130 & Loading DG sources \\
\hline
\end{tabular}

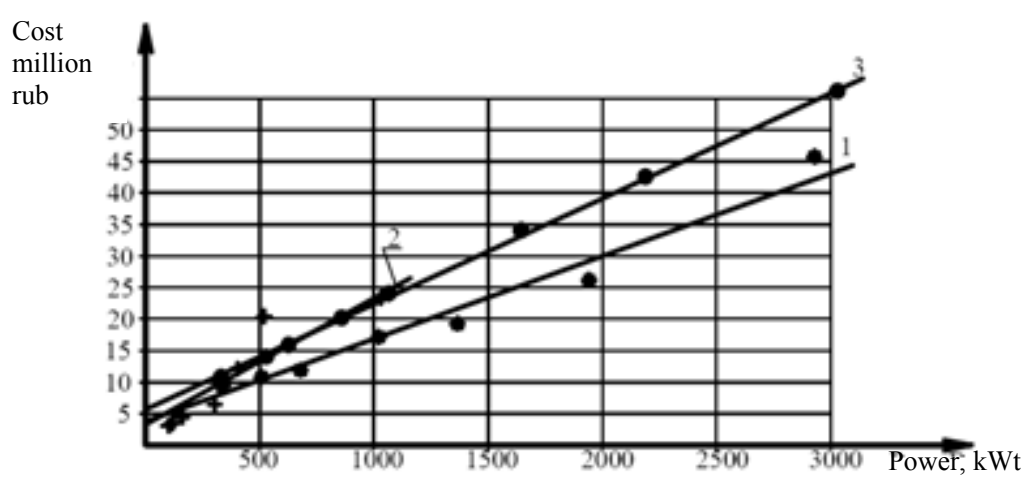

Figure 3: The cost of generators (Deutz company).

Likewise, there are also other components of the model.

Capital expenditures for the construction part and assembly units and turnkey engineering systems:

$$
K_{1}=\sum_{i=1}^{N}\left(n_{i}+n_{p i}\right) \cdot\left(a_{3}+a_{4}\right) \cdot P_{D G i}
$$

where $a_{3}$ and $a_{4}$ - coefficients of the linear dependence of the cost of construction and installation of the power units.

Transportation costs are modeled by the following expression, also have a linear relationship:

$$
K_{1}=\sum_{i=1}^{N}\left(n_{i}+n_{p i}\right) \cdot\left(a_{5}+a_{6}\right) \cdot P_{D G i}
$$

where $a_{5}, a_{6}-$ coefficients of the linear approximation of a function depending on the cost of delivery of the generator power $P_{\text {ri }}$ to the installation site.

Besides capital costs through the linearized function are operating costs. 
In Table 1, the enumeration begins with the operating costs of losses in the distribution network of 6-35 kV. The cost of power losses:

$$
C_{1}=\sum_{i=1}^{M}\left(h_{1 i} \cdot \Delta W\right)
$$

where $\mathrm{h}_{1 \mathrm{j}}$ - tariff for electricity in the $\mathrm{j}$-th time interval, USD/kW Wh; $\Delta \mathrm{W}_{\mathrm{j}}-$ loss of grid electricity in the $\mathrm{j}$-th time interval, $\mathrm{kW} \mathrm{h,} \mathrm{M}$ - number of time intervals into which the daily load curve .

Other costs are modeled on analogical principles.

\section{Discussion and conclusion}

Although the model does not account for all the many influencing factors, but many of these factors can be taken into account as the target constraints. For example, on a limited budget, the construction of the source DG maximum amount of possible investment funds can be used as a limitation, you can use environmental restrictions on emissions, noise, and many others. It is worth noting the speed of the algorithm. Calculation results are compared with the results obtained by direct sorting options and a nonlinear method of generalized down-gradient (OPG). All methods give the same results, and for problems with a small number of variants show about the same computation time.

Table 5: Time spent to solve the problem of optimal DG placement.

\begin{tabular}{|c|c|c|c|}
\hline Possible options, $10^{6}$ & GA, sec & Linear programming, sec & Brute force, sec \\
\hline 0.003 & 2 & 3 & 6 \\
\hline 0.01 & 3 & 3 & 8 \\
\hline 0.3 & 4 & 9 & 127 \\
\hline
\end{tabular}

It may be noted that the above model can be used in various problems, such as the selection of the generating equipment at some point in the network, or the selection of the most optimal ways to connect to the parallel operation source $\mathrm{WG}$, as it may be quite a lot of options.

\section{References}

[1] K.-H. Kim, K.-B. Song, S.-K. Joo, Y.-J. Lee, and J.-O. Kim, "Multiobjective distributed generation placement using fuzzy goal programming with genetic algorithm," Eur. Trans. Electr. Power, vol. 18, no. 3, pp. 217230, Apr. 2008.

[2] H. Hedayati, S. A. Nabaviniaki, and A. Akbarimajd, "A method for placement of DG units in distribution networks," IEEE Trans. Power Del, vol. 23, no. 3, pp. 1620-1628, Jul. 2008. 
[3] S. Kotamarty, S. Khushalani, and N. Schulz, "Impact of distributed generation on distribution contingency analysis," Elect. Power Syst. Res., vol. 78, no. 9, pp. 1537-1545, Sep. 2008.

[4] L. Wang and C. Singh, "Reliability-constrained optimum placement of reclosers and distributed generators in distribution networks using an ant colony system algorithm," IEEE Trans. Syst., Man, Cyhern. C, Appl. Rev., vol. 38, no. 6, pp. 757-764, Nov. 2008.

[5] R. K. Singh and S. K. Goswami, "Optimum siting and sizing of distributed generations in radial and networked systems," Elect. Power Compon. Syst., vol. 37, no. 2, pp. 127-145, Jan. 2009.

[6] D. Singh, D. Singh, and K.-S. Verma, "Multiobjective optimization for DG planning with load models," IEEE Trans. Power Syst., vol. 24, no. 1, pp. 427-436, Feb. 2009.

[7] P. M. Costa and M. A. Matos, "Avoided losses on LV networks as a result of microgeneration," Elect. Power Syst. Res., vol. 79, no. 4, pp. 629-634, Apr. 2009.

[8] T. Gozel and M. H. Hocaoglu, "An analytical method for the sizing and siting of distributed generators in radial systems," Elect. Power Syst. Res., vol. 79, no. 6, pp. 912-918, Jun. 2009.

[9] G. N. Koutroumpezis and A. S. Safigianni, "Optimum allocation of the maximum possible distributed generation penetration in a distribution network," Electr. Power Syst. Res., vol. 80, no. 12, pp. 1421-1427, Dec. 2010.

[10] J. M. Lopez-Lezama, J. Contreras, and A. Padilha-Feltrin, "Location and contract pricing of distributed generation using a genetic algorithm," Int. $J$. Electr. Power Energy Syst., vol. 36, no. 1, pp. 117-126, Mar. 2012.

[11] M. F. Akorede, H. Hizam, I. Aris, and M. Z. A. Ab Kadir, "Effective method for optimal allocation of distributed generation units in meshed electric power systems," IET Gener., Transm., Distrib., vol. 5, no. 2, pp. 276-287, Feb. 2011.

[12] F. Rotaru, G. Chicco, G. Grigoras, and G. Cartina, "Two-stage distributed generation optimal sizing with clustering-based node selection," Int. J. Electr. Power Energy Syst., vol. 40, no. 1, pp. 120-129, Sep. 2012.

[13] A. M. El-Zonkoly, "Optimal placement of multi-distributed generation units including different load models using particle swarm optimisation," IET Gener., Transm., Distrib., vol. 5, no. 7, pp. 760-771, Jul. 2011.

[14] L. D. Arya, A. Koshti, and S. C. Choube, "Distributed generation planning using differential evolution accounting voltage stability consideration," Int. J. Electr. Power Energy Syst., vol. 42, no. 1, pp. 196-207, Nov. 2012.

[15] B. Banerjee and S. M. Islam, "Reliability based optimum location of distributed generation," Int. J. Electr. Power Energy Syst., vol. 33, no. 8, pp. 1470-1478, Oct. 2011.

[16] 19A. Ishchenko, J.M.A. Myrzik, and W.L. Kling, "Transient stability analysis of distribution network with dispersed generation", Universities Power Engineering Conference (UPEC 2006), Newcastle, UK, September 2006. 
454 Energy Production and Management in the 21st Century, Vol. 1

[17] Chechushkov D, Panikovskaya T. Some features of the operation of distributed generation sources // Effective and quality supply and use of electrical energy. II International Scientific and Practical Conference of the exhibition "Energy, heating, ventilation, water supply industry and Utilities” 15-17 May 2012. Yekaterinburg. JSC “Ural Exhibitions” 2012. UDC 621.31:338.24 pp 42-45. 